Research Article

\title{
A Study on the Fundamental Quality of Magnesia-Phosphate-Formed Mortar Composites Using Superabsorbent Polymer for Development of Concrete for Biological Panel
}

\author{
Yun-Wang Choi $\mathbb{D}^{1},{ }^{1}$ Sung-Rok Oh $\mathbb{D}^{1},{ }^{1}$ Cheol-Gyu Kim $\mathbb{D}^{1},{ }^{1}$ and Jae-Heun Lee $\mathbb{D}^{2}$ \\ ${ }^{1}$ Department of Civil Engineering, Semyung University, Jecheon 27136, Republic of Korea \\ ${ }^{2}$ Institute of Technology, Eugene Corporation Co. Ltd., Bucheon 14441, Republic of Korea \\ Correspondence should be addressed to Sung-Rok Oh; cgdbs02@nate.com
}

Received 5 January 2018; Revised 20 September 2018; Accepted 26 September 2018; Published 1 November 2018

Guest Editor: Rujie He

Copyright ( $) 2018$ Yun-Wang Choi et al. This is an open access article distributed under the Creative Commons Attribution License, which permits unrestricted use, distribution, and reproduction in any medium, provided the original work is properly cited.

\begin{abstract}
The purpose of this study was to investigate the base material of the biological panel as one of the researches for developing the biological panel using (micro)organisms. In order to select the base material for the biological panel, the applicability of the magnesia-potassium-phosphate-foamed mortar composites material using the superabsorbent polymer was evaluated through the evaluation of basic quality and characteristics. Experiments were conducted to evaluate the fluidity, compressive strength, $\mathrm{pH}$, roughness (porosity distribution), and moisture retention (absorbency) of the magnesia-phosphate-foamed mortar composites according to the additional amount of the superabsorbent polymer. Experimental results showed that the addition of a suitable superabsorbent polymer can provide good results in terms of compressive strength, workability, and moisturizing properties (absorbency). As a result, it can be used as a basic quality study data of the biological panel design.
\end{abstract}

\section{Introduction}

Due to the rapid industrial revolutions around the world and indiscriminate urban development, there is a series of serious environmental problem such as increase of $\mathrm{CO}_{2}$ emissions, fine dust generation, and increase of cooling energy use due to reduction of the green area $[1,2]$. In order to solve this problem, various researches and efforts have been carried out both domestically and externally in order to develop ecofriendly construction materials. However, most of them have been focused on waste resource utilization, carbon abatement type, and environmentally friendly concrete technology [310]. These technologies can solve the problem of $\mathrm{CO}_{2}$ reduction, but it is difficult to take alternative measures to heat island phenomenon and increase of cooling energy use due to increase of city's atmospheric temperature.

In order to compensate for this, there is a way to solve the problem by installing a vertical garden inside and outside the building, but it is difficult to integrate with the exterior wall of the structure. In addition, complex support structures and expensive maintenance and installation costs increase about three times as compared to the common garden of the same area, making it difficult to commercialize them economically [11]. Although there are sponge, mat type, block type, and lightweight soil, similar to the vertical garden, there are many durability problems [12-17].

To solve this problem, biological panels can be developed and integrated with the structure. Biological panels should be easy to put on (biology), etc., and environment should be created so that it can survive after it is rooted. However, when cement is used as a material for panel fabrication, it forms a high $\mathrm{pH}$, which makes it unsuitable for survival and maintenance of living (micro)organisms [18]. In addition, smooth or dense surface makes it difficult to attach (micro) organisms, and similarly problems arise with nutrients and water supply for (micro)organisms [19].

As one of the basic studies for the development of biological panels, it was investigated whether the 
magnesia-phosphate-foamed mortar composites used the superabsorbent polymer. Unlike conventional cement, magnesium-phosphate composites can form neutral $\mathrm{pH}$ [19]. In addition, air bubbles can form pores on the surface and inside the matrix, and adsorption of nutrients in the air through the pores can be beneficial for the growth of living (micro)organisms [19].

In addition to these, porous surfaces are important, and their supply to moisture also plays a very important role in the growth of living (micro)organisms. In order to achieve such a purpose, the superabsorbent polymer can be applied. The superabsorbent polymer can absorb more than several times its own mass of moisture, and the absorbed moisture gradually dries. When the superabsorbent polymer is applied to the biological panel, the moisture retention of the panel can be improved.

Accordingly, even in a dry environment, the absorbed moisture of the superabsorbent polymer can be utilized for the purpose of moisture supply of (micro)organisms [19].

Therefore, in this study, a magnesium-phosphatepotassium-formed mortar composites using a superabsorbent polymer was prepared as a parent material of the biological panel, and basic quality characteristics and biological characteristics were examined. The results of this study are used to reflect the quality of the biological panel design.

\section{Experiment Outline}

\subsection{Experimental Materials}

2.1.1. Magnesia-Potassium-Phosphate Cement Mortar Composites. The magnesia cement used in this experiment was dead magnesia ( $\mathrm{MgO}$, hereinafter referred to as "M") with a density of $3.6 \mathrm{~g} / \mathrm{m}^{3}$ fired at a high temperature of $1,500^{\circ} \mathrm{C}$ or more. As a curing agent which reacts with dead magnesia, potassium monophosphate $\left(\mathrm{KH}_{2} \mathrm{PO}_{4}\right.$, hereinafter referred to as "P") having a purity of $99 \%$ or more and a density of $2.34 \mathrm{~g} / \mathrm{m}^{3}$ was used. In addition, boric acid $\left(\mathrm{H}_{3} \mathrm{BO}_{3}\right.$, hereinafter referred to as " $\mathrm{R}$ ") was used as a retarding agent in consideration of its workability, and silicate no. 8 (hereinafter referred to as "S") of $95 \%$ or more of $\mathrm{SiO}_{2}$ was used as an fine aggregate. Magnesia cement requires a retarder for workability due to fast curing time. And since it is made of a dense ceramic structure, it exhibits high strength of about $40 \mathrm{MPa}$ in a short time.

Table 1 shows the chemical composition and physical properties of materials used in the experiment.

2.1.2. Foaming Agent. The foaming agent used in this experiment was sodium bicarbonate $\left(\mathrm{NaHCO}_{3}\right.$, hereinafter referred to as " $F$ ") which reacted with potassium ions and reacted with acid ions to generate bubbles. $\mathrm{F}$ is a suitable foaming agent that combines with ions generated by an acidbase neutralization reaction to generate a gas, and the chemical reaction formula can be expressed as follows:

$$
\mathrm{HCO}_{3}^{-}+\mathrm{H}^{+} \longrightarrow \mathrm{CO}_{2}+\mathrm{H}_{2} \mathrm{O}
$$

The bubbles created through this bond create a rough surface through the voids inside and outside the mortar,
TABle 1: The physical and chemical composition of the materials used in the experiments.

\begin{tabular}{lccccc}
\hline Type & $\begin{array}{c}\text { Purity } \\
(\%)\end{array}$ & $\begin{array}{c}\mathrm{Al}_{2} \mathrm{O}_{3} \\
(\%)\end{array}$ & $\begin{array}{c}\mathrm{SiO}_{2} \\
(\%)\end{array}$ & $\begin{array}{c}\mathrm{MgO} \\
(\%)\end{array}$ & $\begin{array}{c}\text { Density } \\
\left(\mathrm{g} / \mathrm{m}^{3}\right)\end{array}$ \\
\hline $\mathrm{M}$ & 96 & 0.1 & 1.1 & 95.6 & 3.6 \\
$\mathrm{P}$ & 99 & - & - & - & 2.34 \\
$\mathrm{R}$ & 99.5 & - & - & - & 1.4 \\
$\mathrm{~S}$ & 95 & - & 95 & - & 2.65 \\
\hline
\end{tabular}

which facilitates the absorption and storage of water and the adsorption of nutrients in the atmosphere [20].

2.1.3. Superabsorbent Polymers (SAP). The superabsorbent polymer used in this study was an acrylic acid polymer, sodium salt (sodium polyacrylate). The superabsorbent polymer is a white powder which is capable of absorbing water several hundred times its own weight. When the water is absorbed, the volume expands and reaches gel state. The swelling characteristics of such a superabsorbent polymer vary depending on the interparticle density, the chemical structure of the superabsorbent polymer, the $\mathrm{pH}$ of the absorbed liquid, the temperature, and the ion concentration.

2.1.4. Experimental Plan. In this study, first, data were collected for magnesium-phosphate-formed mortar composites (SMPFC) using the superabsorbent polymer. Through preliminary experiments, the data of more than $10 \mathrm{MPa}$ of the target strength were obtained by using the water/binder ratio (W/B) $30 \%, \mathrm{MgO}: \mathrm{KH}_{2} \mathrm{PO}_{4}$ ratio (P:M) $1: 0.5$, fine aggregate volume/total mortar volume ratio $(\mathrm{Vs} / \mathrm{Vm}) 10 \%$, retardation $3 \%$, and foaming agent $0.5 \%$. Therefore, 4 levels $(0.25,0.5$, 0.75 , and $1.0 \%$ ) were prepared for data acquisition according to SAP addition. In addition, the flow characteristics, compressive strength, $\mathrm{pH}$, roughness, and moisture retentivity were measured. The bubbles were applied in the postfoaming mode. The compressive strength was set to $10 \mathrm{MPa}$ or more in terms of landscaping design at 6 hours, 1 day, 3 days, and 7 days of age in accordance with the characteristics of magnesia cement. Table 2 shows the mixing ratio of SMPFC used in the experiment.

\subsection{Experimental Method}

2.2.1. Mixing of SMPFC. The SMPFC was subjected to dry mixing with $M, P, R$, and SAP for about 2 minutes. Then, the blend was then mixed with the compounding water for 2 minutes at the low speed and then for 3 minutes at the high speed. Thereafter, additional water containing $\mathrm{F}$ was added, and the mixture was further mixed at the high speed for one minute.

2.2.2. Extra Water (eW) Decision. SAP rapidly absorbs moisture when exposed to moisture. Also, the amount of absorbed water increases with time. For this reason, the unit water quantity sharply decreases, the fluidity decreases, and the workability decreases. In addition, magnesia cement 
TABle 2: Mix design.

\begin{tabular}{|c|c|c|c|c|c|c|c|}
\hline \multirow{2}{*}{ Type } & \multirow{2}{*}{$\mathrm{W} / \mathrm{B}(\%)$} & \multicolumn{2}{|c|}{ Binder } & \multirow{2}{*}{$\mathrm{R}$} & \multirow[b]{2}{*}{$\mathrm{F}$} & \multirow{2}{*}{ SAP } & \multirow{2}{*}{ Extra water $(\mathrm{eW})$} \\
\hline & & $\mathrm{P}$ & M & & & & \\
\hline SMPFC-P & & & & & & - & - \\
\hline SMPFC-0.25 & & & & & & $0.25 \%$ on binder & $10 \%$ on $\mathrm{W}$ \\
\hline SMPFC-0.5 & 35 & 1 & 0.5 & $3 \%$ on $\mathrm{M}$ & $0.5 \%$ on binder & $0.5 \%$ on binder & $16 \%$ on $\mathrm{W}$ \\
\hline SMPFC-0.75 & & & & & & $0.75 \%$ on binder & $22 \%$ on $\mathrm{W}$ \\
\hline SMPFC-1.0 & & & & & & $1.0 \%$ on binder & $27 \%$ on $\mathrm{W}$ \\
\hline
\end{tabular}

requires a large amount of unit water, unlike ordinary cement. This problem can be solved by adding additional water [21].

Previous studies have shown that SAP exhibits maximum absorption after 10 minutes of contact with water and is shaped like a gel [22]. Therefore, additional water should be added before reaching maximum absorption.

As a result of the preliminary test, it was found that, to achieve the target slump, extra water should add about $6 \%$ of the unit water when the SAP is increased by $0.25 \%$.

2.2.3. Flow. The flow of SMPFC was measured in accordance with the "KS L 5105 Hydraulic Cement Mortar Compressive Strength Test Method".

2.2.4. Compressive Strength. The compressive strength of SMPFC was cubic-type specimens of $50 \mathrm{~mm} \times 50 \mathrm{~mm} \times$ $50 \mathrm{~mm}$ prepared according to "KS L 5105 Compressive Strength Test Method of Hydraulic Cement Mortar," followed by curing. Afterwards, the sample was demolded, and the compressive strength was measured by universal testing (UTM) at each age.

2.2.5. $p H$. The $\mathrm{pH}$ of SMPFC was measured in accordance with KS M 0011 "Method for measuring $\mathrm{pH}$ of aqueous solution." Also, the $\mathrm{pH}$ of SMPFC was measured according to age.

2.2.6. Surface Roughness. The roughness measurement of SMPFC was measured by relative comparison with the surface of the bubble-free reference specimen. Roughness is an important factor in the application of biological panels because it is one of the indicators to induce adsorption on the surface of rainwater or nutrients in the air.

2.2.7. Moisturizing Property. The moisture retention (moisture content) of SMPFC was measured by wetting curing of the specimen for one day according to KS F 2459 "Test method of apparent density, water content, water absorption, and compressive strength of foam concrete". Thereafter, the mass of the dried sample in the drying furnace was measured.

\section{Experimental Results and Discussion}

3.1. Flow. Figure 1 shows the flow measurement result according to the addition amount of SAP of SMPFC. As a result of the experiment, the flow value decreased by about

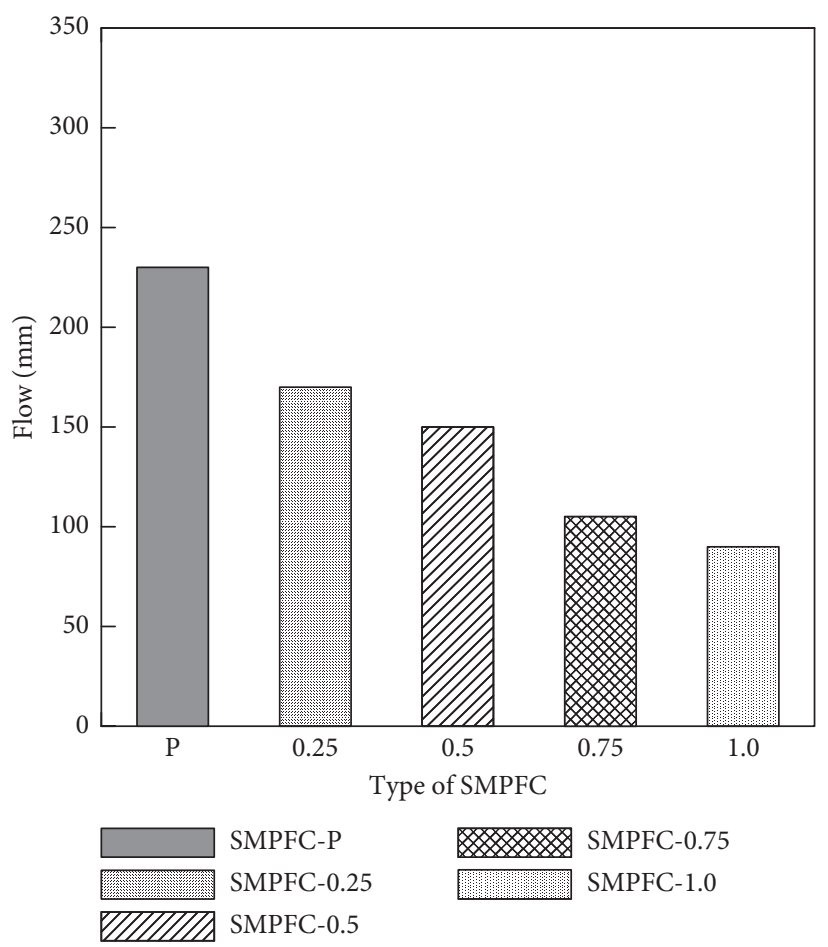

Figure 1: Test results of flow (extra water not added).

$10 \%$ every time the SAP addition amount was increased by $0.25 \%$ without determining the additional extra water $(\mathrm{eW})$. The cause of this phenomenon is considered to be the property of absorbing moisture of SAP. However, if eW is added as shown in Figure 2, the target flow can be satisfied.

3.2. Compressive Strength. Figures 3-6 show the results of compressive strength measurement according to the additional amount of SAP of SMPFC, and the results of the compressive strength test at 6 hours, 1 day, 3 days, and 7 days of age are shown. The compressive strength at 6 hours did not achieve the target strength in all cases. Also, the compressive strength at 1 and 3 days was more than $10 \mathrm{MPa}$ for plain. A mix with SAP that could achieve the target intensity was possible after 7 days. The compressive strength of SAP $0.25 \%$ at 7 days was above $12 \mathrm{MPa}$ and decreased proportionally with increasing SAP. The compressive strength of SAP $0.5 \%$ was about $8 \mathrm{MPa}$, and the compressive strength of SAP 0.75 and $1.0 \%$ was less than $5 \mathrm{MPa}$ lower than the target strength. Overall, as the amount of SAP increased, the compressive strength decreased, and the specimen with $1.0 \%$ SAP was easily destroyed. However, when the addition 


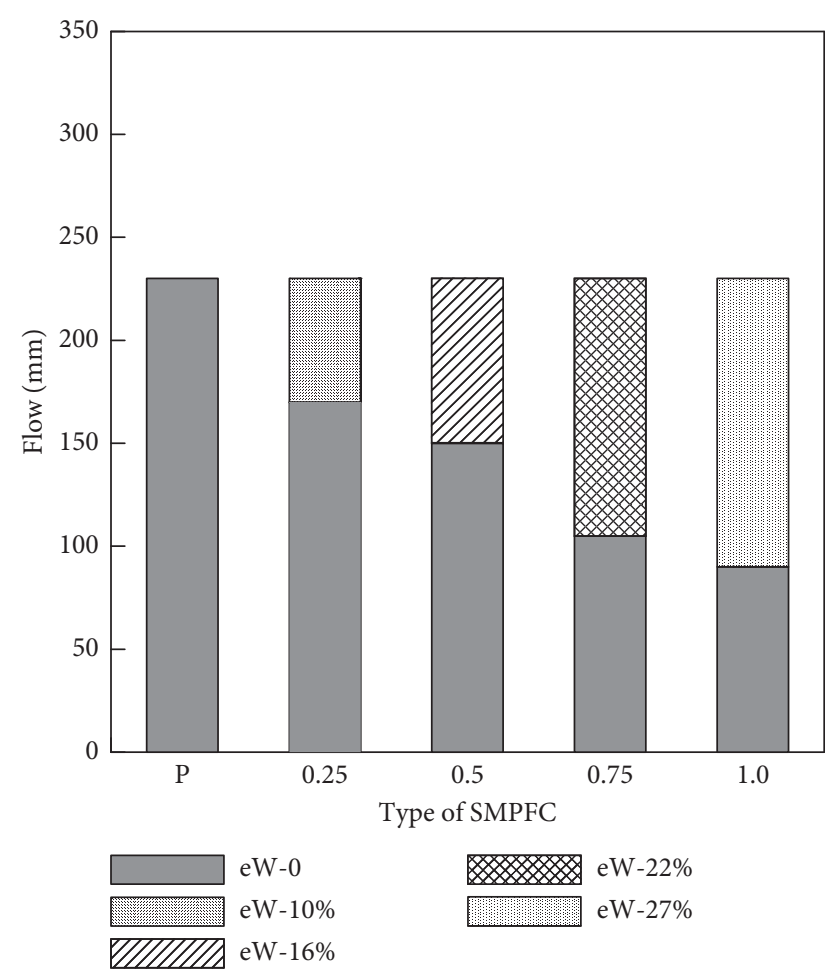

FIgURE 2: Test results of flow (extra water added).

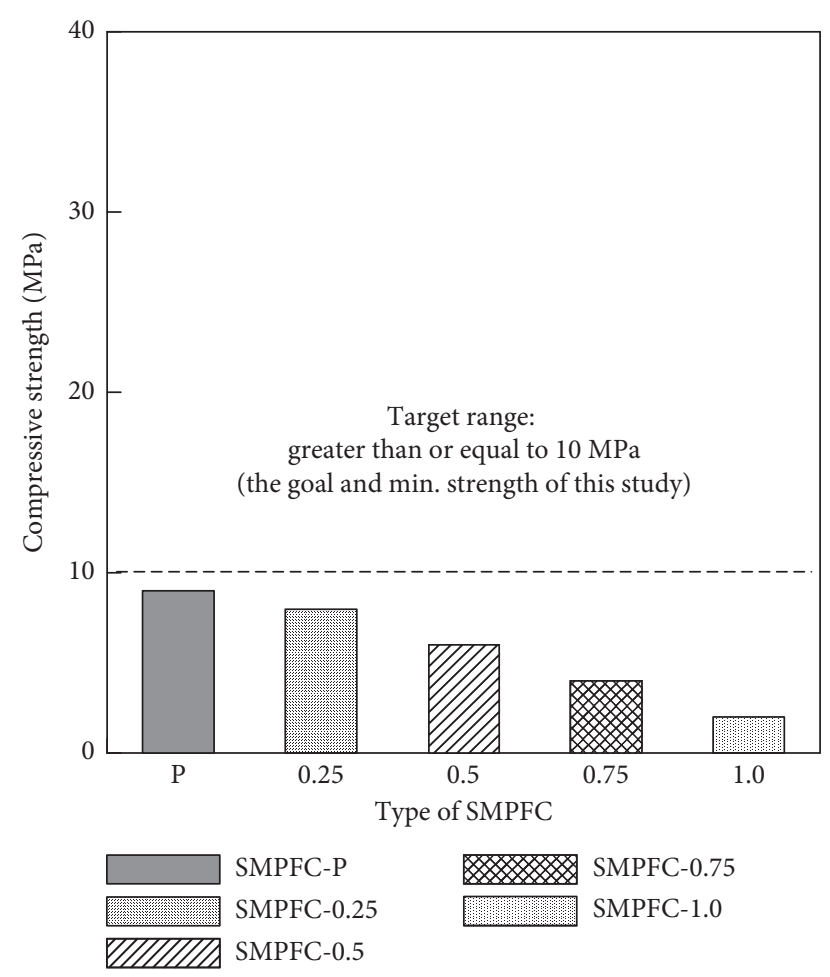

Figure 3: Test results of compressive strength $(6 \mathrm{H})$.

amount of SAP was $0.25 \%$, similar results were obtained. Therefore, if the optimum amount of SAP is to be found, it will be possible to control the strength when applying the biological panel.

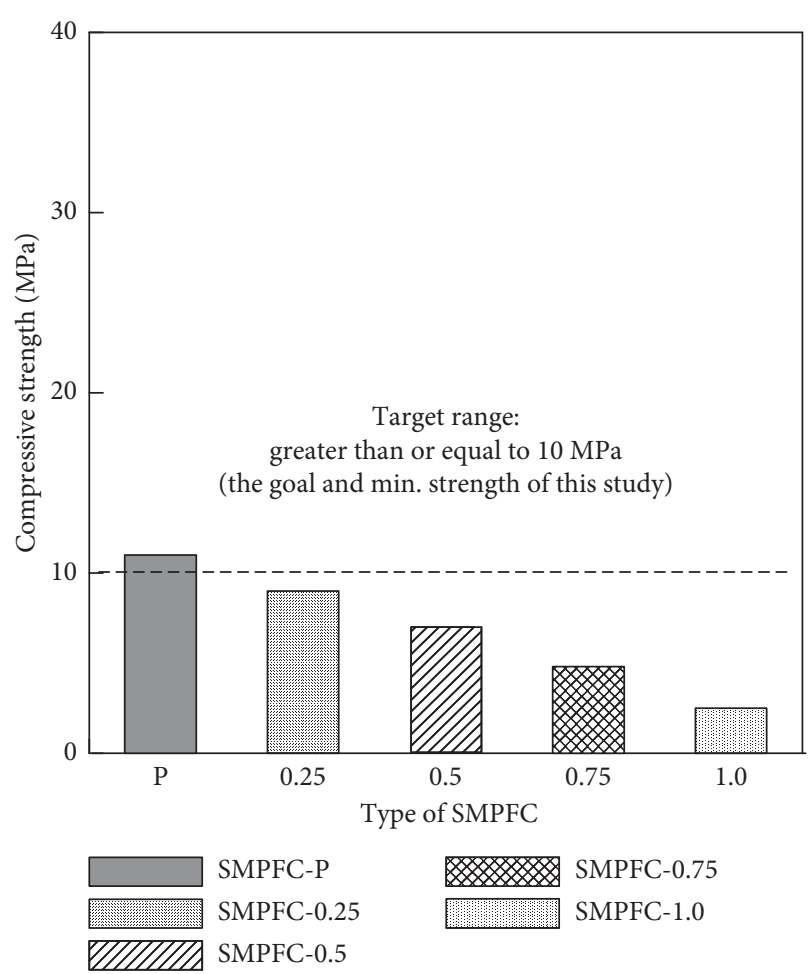

FIgURE 4: Test results of compressive strength (1D).

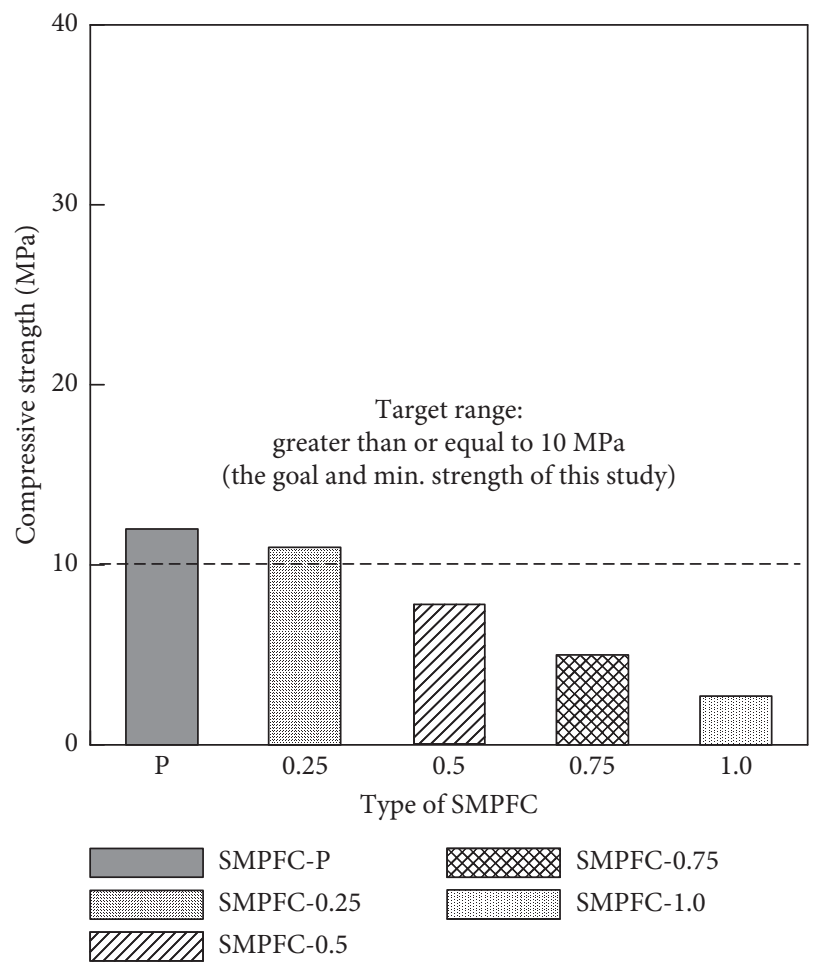

FIgURE 5: Test results of compressive strength (3D).

3.3. $p H$. Figure 7 shows the $\mathrm{pH}$ measurement results of SMPFC at 6 hours, 1 day, 3 days, and 7 days. As a result of the experiment, the $\mathrm{pH}$ of the specimen tended to increase with age. Magnesia cement was measured at $\mathrm{pH}$ 7-9 


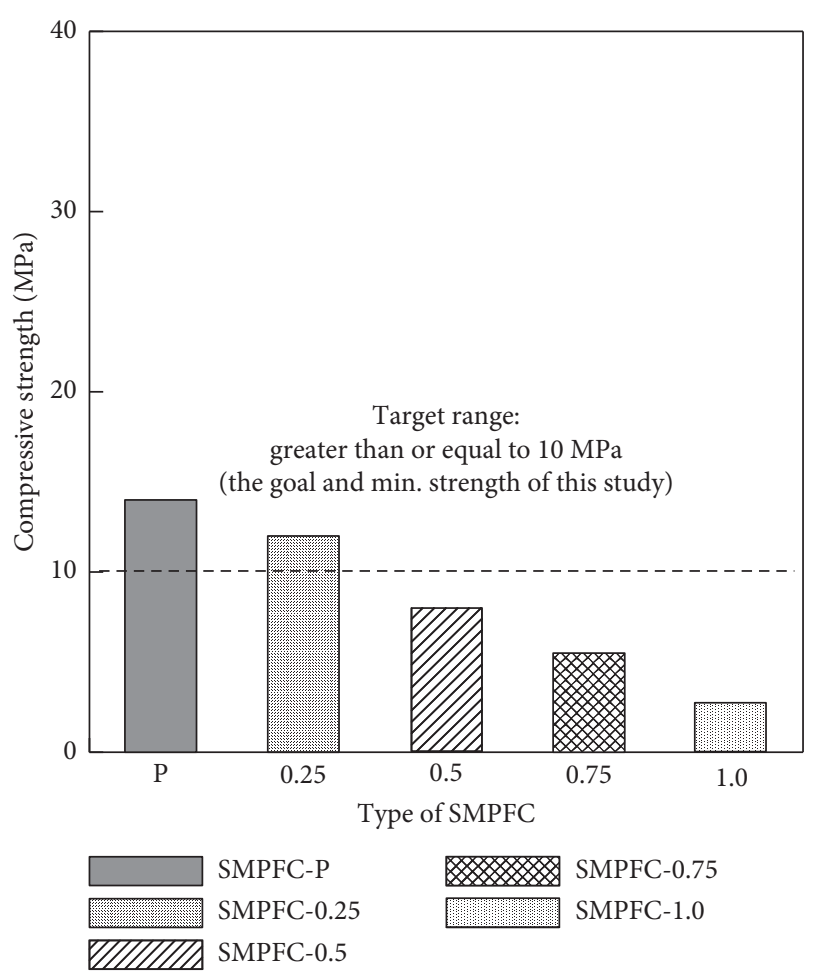

FIGURE 6: Test results of compressive strength (7D).

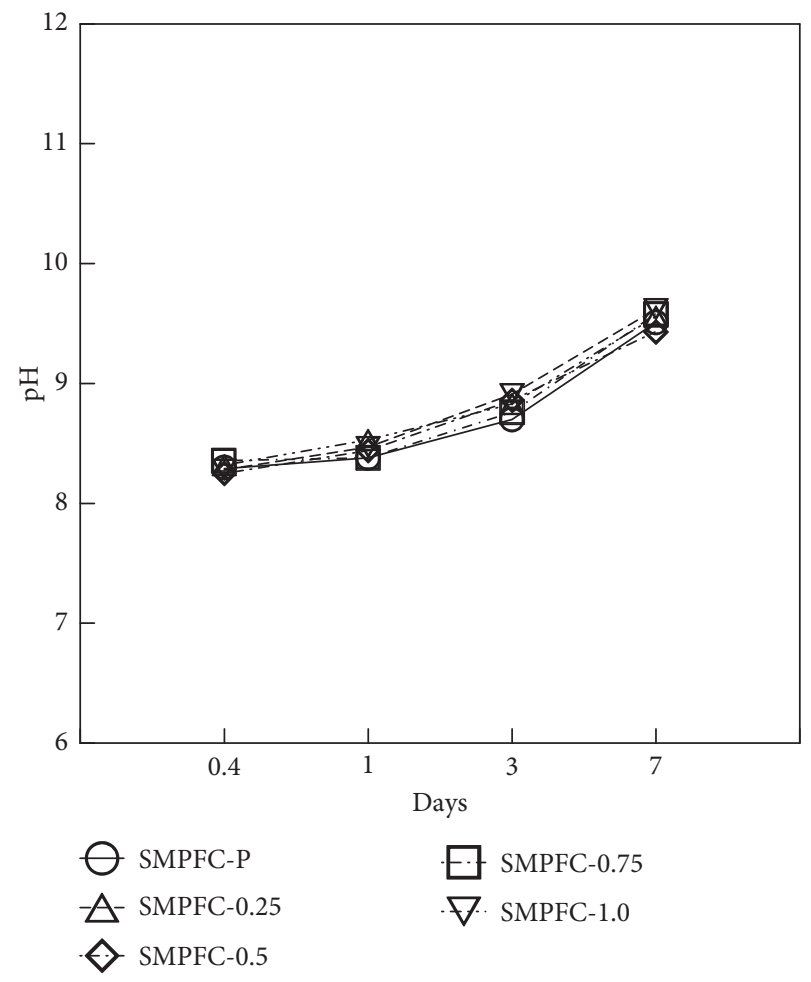

Figure 7: pH measurement results of SMPFC.

depending on the type of the phosphate used in the formulation. The SAP used in the experiment was a material with a $\mathrm{pH}$ of 6.5 and showed no significant effect on the $\mathrm{pH}$ change of SMPFC. The $\mathrm{pH}$ at 7 days was measured as 9. Since the matrix for biological panels is important for the survival of (micro)organisms, it is necessary to examine the $\mathrm{pH}$. From these results, SMPFC, which is a neutral region, would be a favorable condition for the survival environment of (micro)organisms.

3.4. Surface Roughness. Figure 8 shows the result of measuring the surface roughness of the SMPFC. It found that the pore depths of the $0.25 \%$ are in the range of $1.0-0.005 \mathrm{~mm}$ and the pore depths of the $0.5 \%$ SAP additions are in $0.1 \mathrm{~mm}$. And pores visible by the naked eye were observed from the micropores.

In the case of $0.75 \%$ and $1.0 \%$ of SAP additions, SAP was observed on the surface because the amount of SAP added was too large. In addition, it was confirmed that the effect of the foaming agent was hardly observed. The reason for this is that a considerable amount of SAP absorbs moisture quickly and suppresses bubble generation. Figure 9 shows the distribution of voids on the surface of the bubbled test piece. These results suggest that SMPFC with a rough surface due to bubbles will be an advantageous growth condition of (micro)organisms and will be advantageous for the adsorption of nutrients in the air.

3.5. Moisturizing Property. Figures 10-14 show the measurement results of moisture content (moisture content) according to the addition amount of SAP of SMPFC. The test roughly evaluated the amount of moisture absorbed by the test piece and SAP through the pores generated on the inside and the surface of the test piece. A qualitative evaluation was performed on the assumption that the larger the pores, the more the SAP could contain in the pores and absorb a large amount of water. The weight of the dried specimen was measured first, and then, the weight of the specimen immersed in water for one day was measured. Then, the period of reaching the dry weight at room temperature was measured.

As shown in Figures 10-14, the moisture retention of SMPFC-P was about $10 \%$ larger than that of dry weight. And SMPFC-0.25 was 5\% higher than SMPFC-P. As the SAP increased by $0.25 \%$, it increased continuously by about $5 \%$. These results show that the amount of SAP added affects the moisture retention, and the sample without SAP showed a drying time about 3 days faster than the sample with SAP added. As the amount of SAP increased, the drying time at room temperature tended to increase by 2 to 3 days compared to that of SMPFC-P. In the case of the sample with $1.0 \%$ SAP content, the complete drying time was about 9 to 10 days. These results suggest that when applied as a matrix for biological panels, the addition of SAP improves the moisture retention and absorbs moisture in the air, which may have a positive effect on the growth of the organism. However, when the amount of SAP increases, it will decrease in compressive strength and durability. Therefore, the optimal amount of SAP should be reviewed. Figure 15 shows the SAP that absorbed moisture inside the test.

These results suggest that SMPEC with improved moisture retention by SAP may contribute to the water supply of (micro)organisms to some extent. In addition, it is 


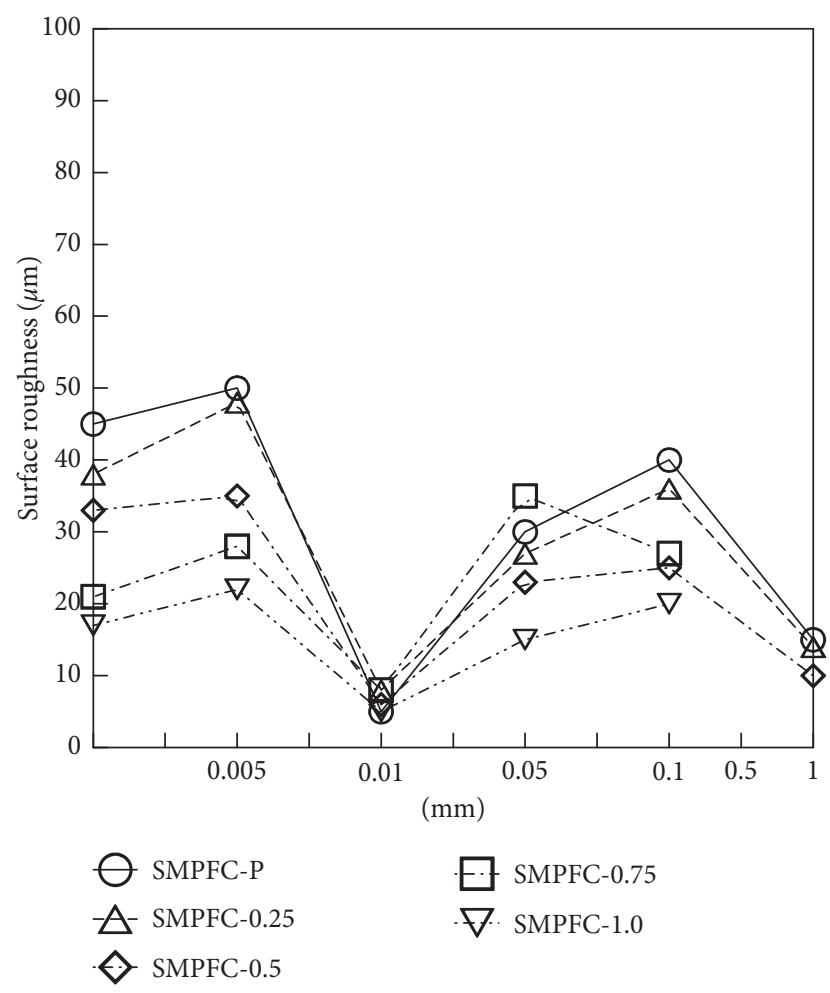

FIgURE 8: Surface roughness results of SMPFC.

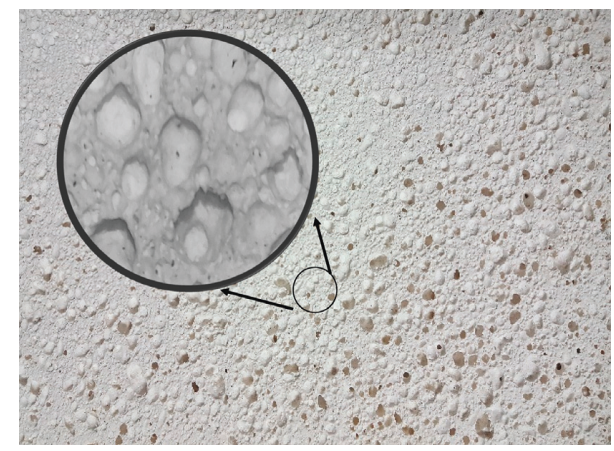

Figure 9: Surface of SMPFC.

considered that the moisturizing effect in the atmospheric moisture or rainy weather will be further increased.

\section{Conclusion}

As one of the basic studies for the development of biological panels, it is investigated that the magnesia-phosphatefoamed mortar composites using the superabsorbent polymer. The following conclusions were obtained:

(1) The magnesia-potassium-phosphate-foamed mortar composites using a superabsorbent polymer were able to satisfy the target flow when extra water was added according to the mixing ratio of the superabsorbent polymer.

(2) The magnesia-potassium-phosphate-foamed mortar composites using a superabsorbent polymer showed a tendency to decrease in compressive strength
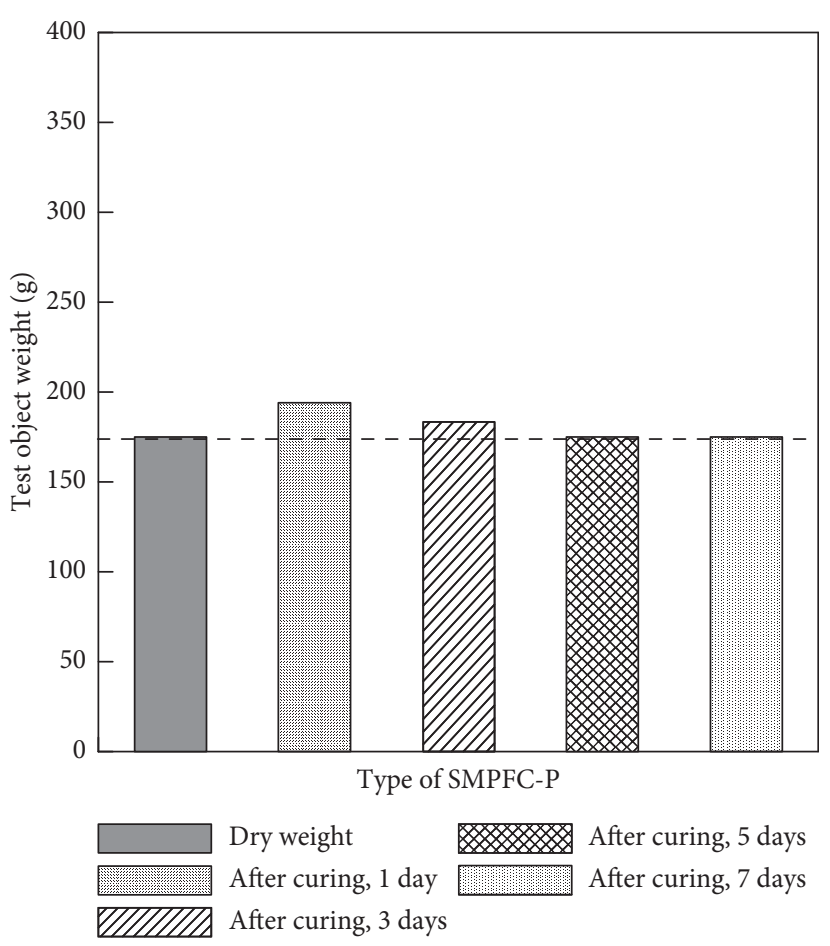

FIgURE 10: Test results of moisture content (plain).

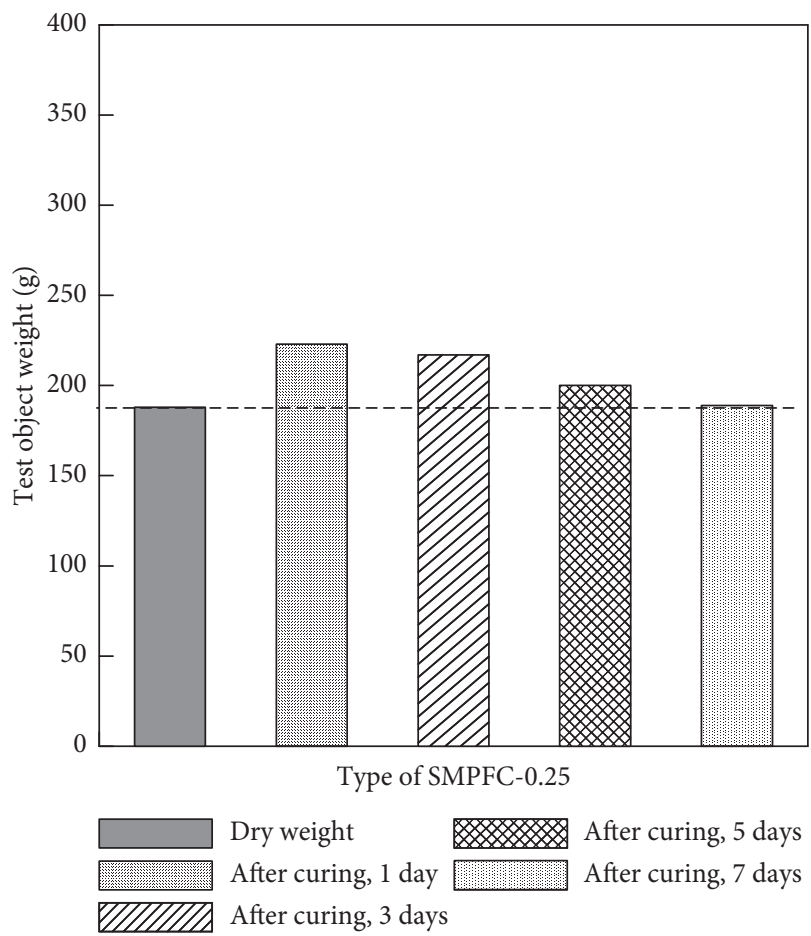

FIgURE 11: Test results of moisture content (SAP 0.25\%).

depending on the mixing ratio of the superabsorbent polymer. The mixing ratio of the superabsorbent polymer satisfying the target strength was found to be within $0.25 \%$.

(3) The magnesia-potassium-phosphate-foamed mortar composites using a superabsorbent polymer 


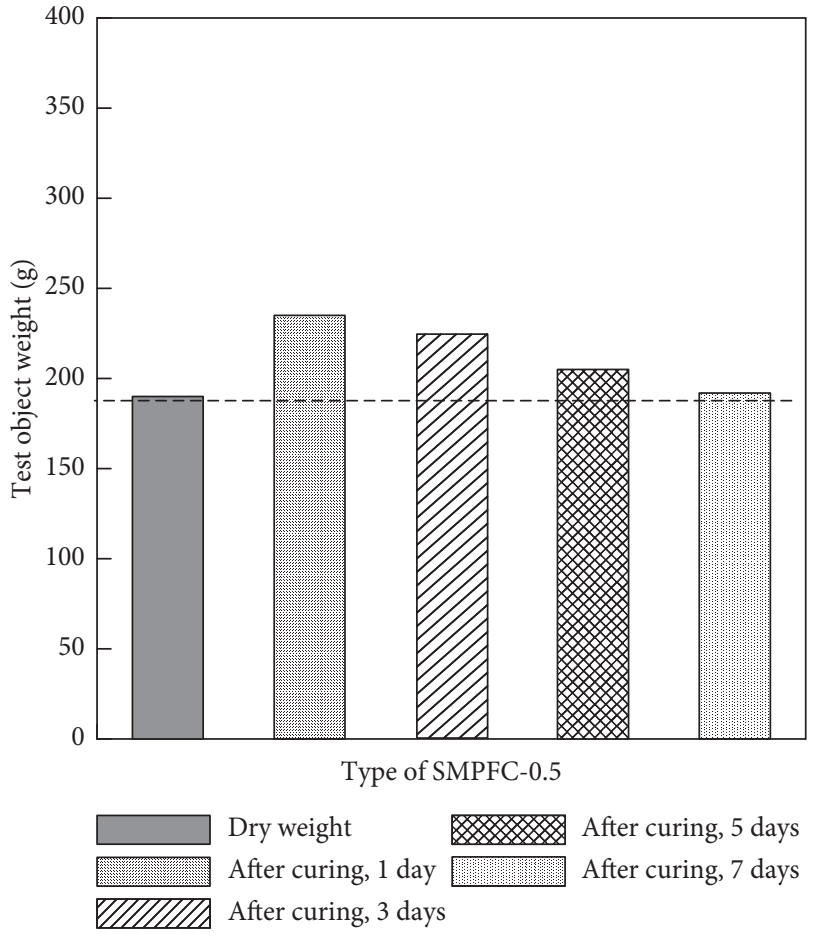

FIgURE 12: Test results of moisture content (SAP 0.50\%).

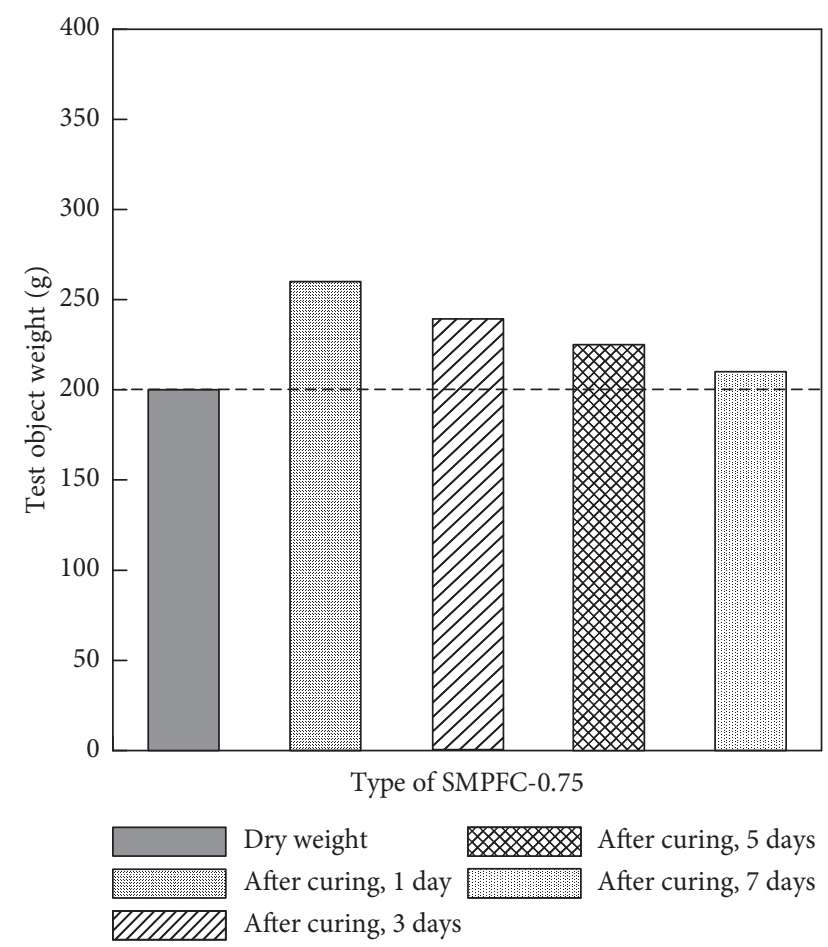

FIGURE 13: Test results of moisture content (SAP 0.75\%).

showed a tendency to increase in water content according to the mixing ratio of the superabsorbent polymer. It also formed a roughened surface by bubbles.

From these results, it was confirmed that the optimum range of the superabsorbent polymer satisfying the

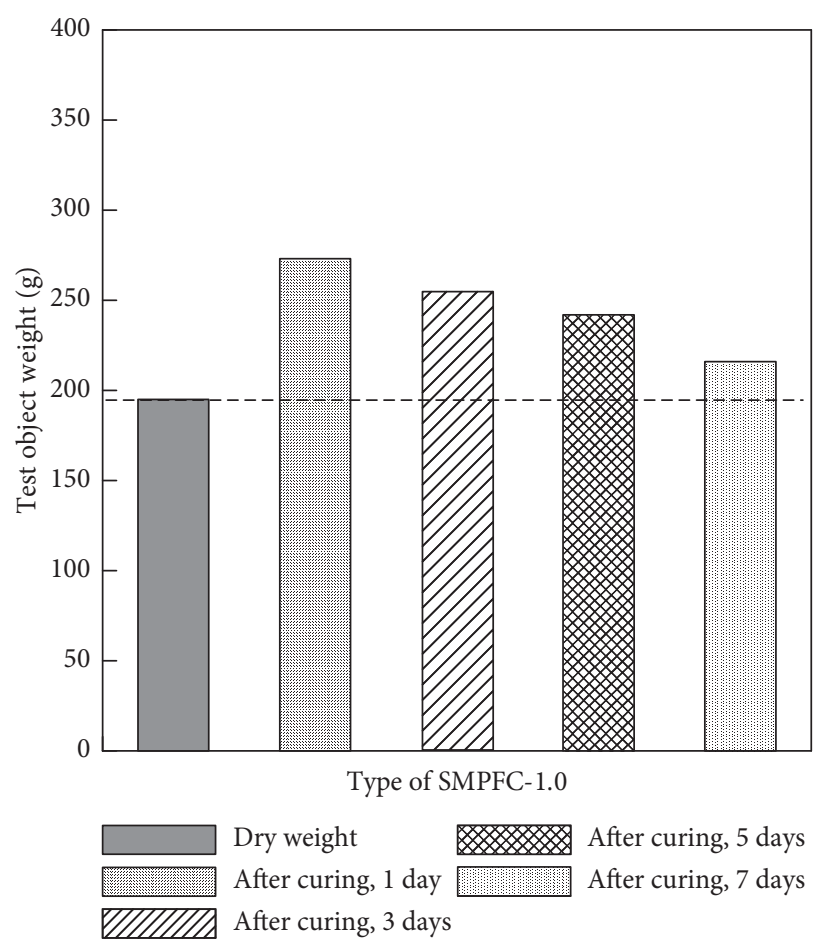

FIgURE 14: Test results of moisture content (SAP 1\%).
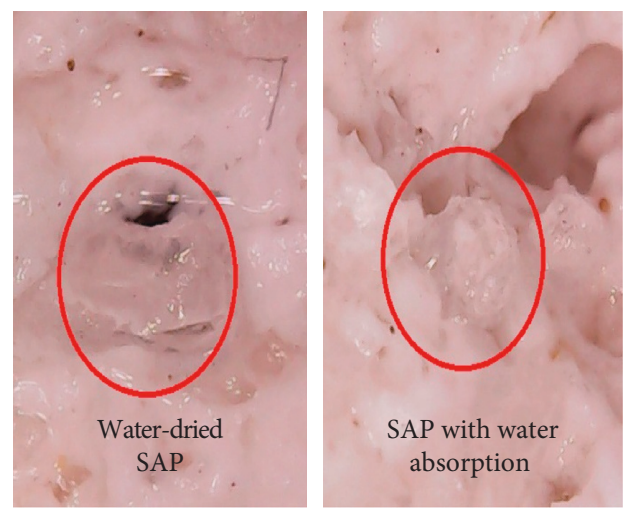

FIGURE 15: SAP absorbed inside the specimen.

target strength was $0.25 \%$. In addition, the rough surface by the foaming agent and the moisture retention by a superabsorbent polymer will be beneficial to rooting and growth conditions of (micro)organisms. As a sequential study, studies on biological acceptability and the growth of (micro) organisms should be accompanied.

\section{Data Availability}

The data used to support the findings of this study are available from the corresponding author upon request.

\section{Conflicts of Interest}

The authors declare that there are no conflicts of interest regarding the publication of this paper. 


\section{Acknowledgments}

This research was supported by a grant (17CTAP-C11464602) from Construction Technology Research Program funded by Ministry of Land, Infrastructure and Transport of Korean government.

\section{References}

[1] K. Perini, M. Ottelé, E. Haas, and R. Raiteri, "Greening the building envelope, façade greening and living wall systems," Open Journal of Ecology, vol. 1, no. 1, pp. 1-8, 2011.

[2] A. Eggert, N. Häubner, S. Klausch, U. Karsten, and R. Schumann, "Quantification of algal biofilms colonising building materials: chlorophyll a measured by PAMfluorometry as a biomass parameter," Biofouling, vol. 22, no. 2, pp. 79-90, 2006.

[3] C. G. Han and S. G. Park, Eco-Friendly Ready Mixed Concrete Using Waste Materials and by-Products, Magazine of the Korea Concrete Institute, Republic of Korea, 2016.

[4] H.-G. Lee, M.-H. Gong, and Y.-S. Jung, Field Application and Manufacturing Technology of Low Carbon Ultra High Strength Green PHC Pile using High Volume Ground Granulated Blast Furnace Slag, Magazine of the Korea Concrete Institute, Republic of Korea, 2016.

[5] T. W. Kim and C. H. Kang, "The self-healing and ageing effect of OPC-GGBFS cement in sea-water and tap-water," Journal of the Korea Concrete Institute, vol. 29, no. 1, pp. 11-21, 2017.

[6] L. Ferrara, V. Krelani, and M. A. Carsana, "Fracture testing based approach to assess crack healing of concrete with and without crystalline admixtures," Construction and Building Materials, vol. 68, pp. 535-551, 2014.

[7] Z. Jiang, W. Li, and Z. Yuan, "Influence of mineral additives and environmental conditions on the self-healing capabilities of cementitious materials," Journal of Cement and Concrete Composites, vol. 57, pp. 116-127, 2015.

[8] I. You, C.-I. Jeong, C. Lyu, G. Lee, and G. Zi, State of Research on High Durable Concrete with Waste Glass Powder for Road Structure, Magazine of the Korea Concrete Institute, Republic of Korea, 2017.

[9] C.-W. Baek, H.-S. Kim, S.-W. Choi, H.-T. Jo, and D.-H. Ryu, "Durability assessment of high strength concrete with high volume mineral admixture," Journal of the Korea Concrete Institute, vol. 27, no. 6, pp. 641-649, 2015.

[10] Y. Halit, Y. Mert, Y. Husyinn, A. Serdar, and T. Selcuk, "Mechanical properties of reactive powder concrete containing high volumes of ground granulated blast furnace slag," Journal of Cement and Concrete Composite, vol. 32, no. 8, pp. 639-648, 2010.

[11] J.-K. Jeon, Y.-S. An, and E.-J. Kim, Performance Evaluation Study on Green-wall System Using Moss, Magazine of the Korea Concrete Institute, Republic of Korea, 2014.

[12] J. S. Lee, S. H. Kim, Y. S. Shin, and C. Hong, "A fundamental experiment of the artificial soil mixture using stone sludge burning pellet for applying to green roof soil," Proceedings of the Korea Concrete Institute, vol. 2012, no. 11, pp. 209-210, 2012.

[13] H.-R. Gkim and T.-M. Ahn, "Cafeteria users' preference for an indoor green-wall in a university dining Hall," Journal of Korean Institute of Landscape Architecture, vol. 43, no. 6, pp. 62-72, 2015.

[14] S. R. Choi, Y. S. Kim, and P. S. Yoon, "The management plan for the maintenance of the green-wall colors-focusing on the eco plaza," in Proceedings of Korean Society of Color Studies, pp. 38-44, 2013.
[15] M. Ottele, K. Perini, A. L. A. Fraaij, E. M. Haas, and R. Raiteri, "Comparative life cycle analysis for green facades and living wall systems," Energy and Buildings, vol. 43, no. 12, pp. 3419-3429, 2011.

[16] K. Perini, M. Ottele, E. M. Haas, and R. Raiteri, "Vertical greening systems, a process tree for green facades and living walls," Urban Ecosystems, vol. 16, no. 2, pp. 1-13, 2009.

[17] H. E Wright Wendel, R. K. Zarger, and J. R. Mihelcic, "Accessibility and usability: green space preferences, perceptions, and barriers in a rapidly urbanizing city in Latin America," Landscape and Urban Planning, vol. 107, no. 3, pp. 272-282, 2012.

[18] T. H. Kim, F. Q. Li, T. W. Ahn, I. S. Choi, and J. M. Oh, "Research on improvement of water purification efficiency by concrete using bio film," Journal of Environmental Impact Assessment, vol. 20, no. 6, pp. 815-821, 2011.

[19] S. Manso, W. D. Muynck, I. Segura et al., "Bioreceptivity evaluation of cementitious materials designed to stimulate biological growth," Science of the Total Environment, vol. 481, pp. 232-241, 2014.

[20] C. Ma and B. Chen, "Experimental study on the preparation and properties of a novel foamed concrete based on magnesium phosphate cement," Construction and Building Materials, vol. 137, pp. 160-168, 2017.

[21] S. H. Kang, J. Moon, and S. G. Hong, "Effect of internal curing by super-absorbent polymer (SAP) on hydration, autogenous shrinkage, durability and mechanical characteristics of ultrahigh performance concrete (UHPC)," Journal of the Korea Concrete Institute, vol. 28, no. 3, pp. 317-328, 2016.

[22] O. M. Jensen and P. F. Hansen, "Water-entrained cementbased materials: II. Experimental observations," Cement and Concrete Research, vol. 32, no. 6, pp. 973-978, 2002. 


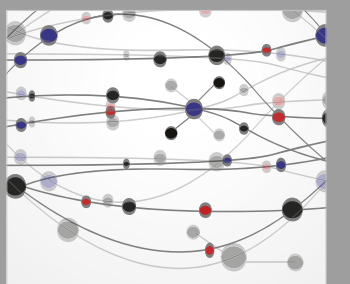

The Scientific World Journal
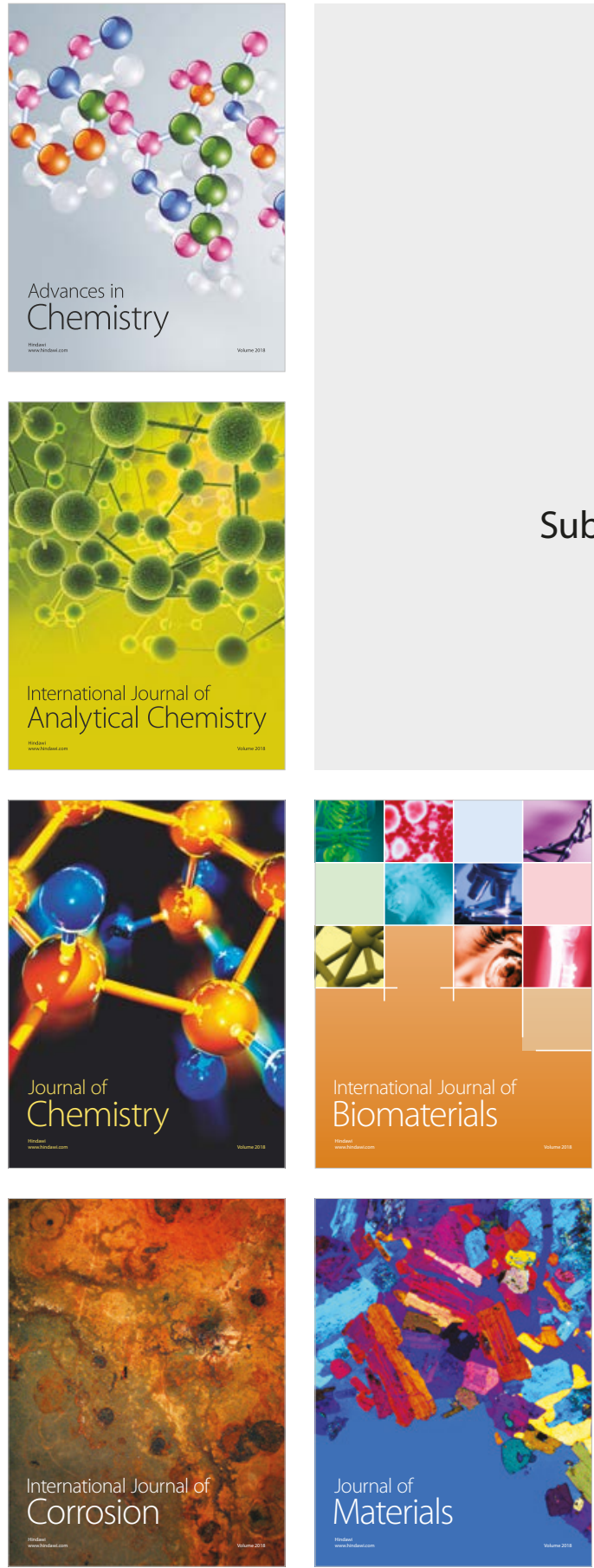

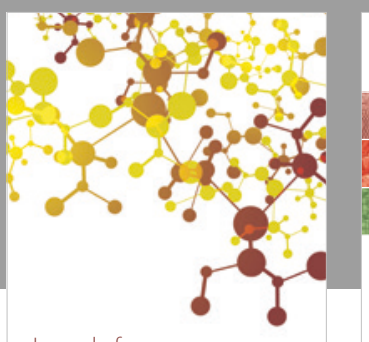

Journal of

Applied Chemistry
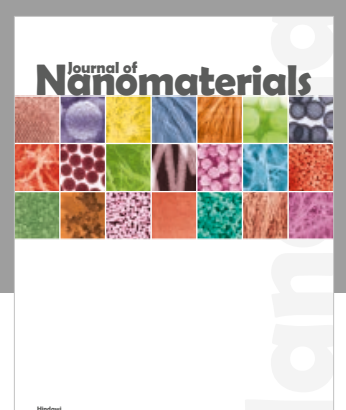

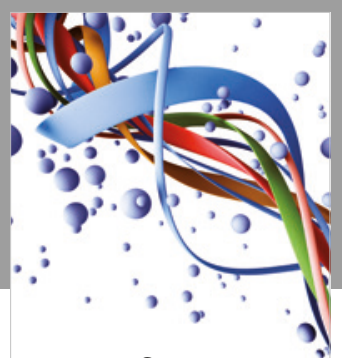

Scientifica

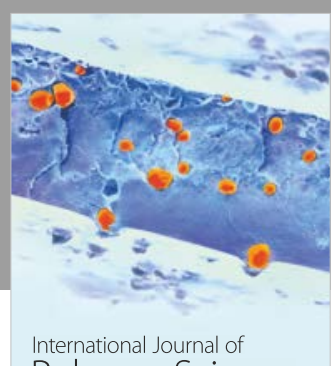

Polymer Science

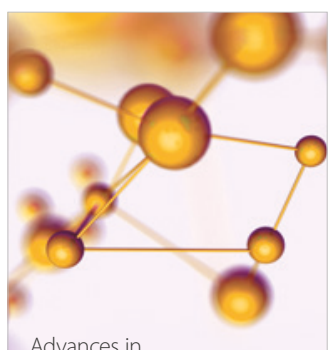

Physical Chemistry
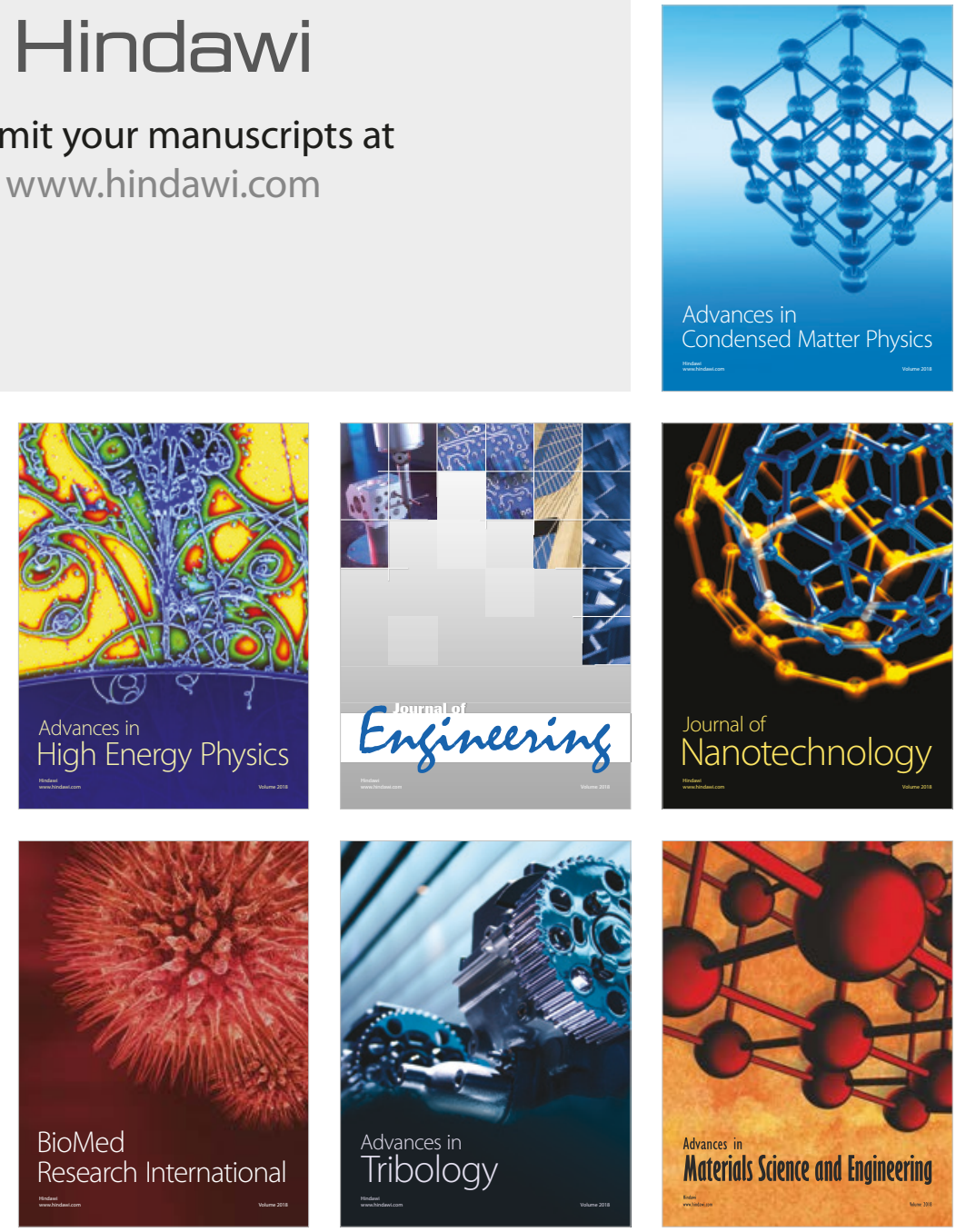